\title{
Topical rebamipide improves the ocular surface in mild lagophthalmos
}

This article was published in the following Dove Press journal:

Clinical Ophthalmology

28 June 2013

Number of times this article has been viewed

\section{Mariko Itakura' \\ Hirotaka Itakura ${ }^{1,2}$ \\ Tomoyuki Kashima ${ }^{2}$ \\ Hideo Akiyama ${ }^{2}$ \\ Shoji Kishi ${ }^{2}$}

'Department of Ophthalmology, Maebashi Red Cross Hospital, Maebashi, Japan; ${ }^{2}$ Department of Ophthalmology, Gunma University, School of Medicine, Maebashi, Japan
Correspondence: Hirotaka Itakura Maebashi Red Cross Hospital,

3-2I-36 Asahi-cho,

Maebashi, Gunma

37|-00 I 4, Japan

Tel +8I 272244585

Fax +8I 272433380

Email itakurah@med.gunma-u.ac.jp
Abstract: Administration of topical rebamipide improves the ocular surface in dry eye. We consecutively studied seven eyes in seven cases (three males and four females) with mild lagophthalmos (three cases after eyelid surgery, two cases of incomplete facial nerve palsy, and two cases of senile ectropion) during the treatment of corneal disorders with rebamipide eye drops four times daily for 2 weeks. The fluorescein corneal staining (FCS) score, tear film break-up time (TBUT), Schirmer's test, and decimal visual acuity were examined. Ocular symptoms were examined and scored by questioning each patient before and after administration of the drug. In all seven eyes, inferior corneal erosion decreased or disappeared within 2 weeks after administration of topical rebamipide. The FCS score was significantly improved $(P<0.05)$. The TBUT was significantly extended from $2.9 \pm 0.5$ seconds to $5.2 \pm 0.4$ seconds $(P<0.05)$. The scores of ocular symptoms, such as eye pain, dryness, blurred vision, and foreign body sensations, were significantly improved $(P<0.05)$. Topical rebamipide was effective for corneal disorders in mild lagophthalmos. This drug may provide a novel approach to treat lagophthalmos.

Keywords: dry eye, ectropion, eyelid surgery, facial nerve palsy, lagophthalmos, rebamipide

\section{Introduction}

Lagophthalmos is the incomplete closure of the eyelids. ${ }^{1}$ The inability to blink and effectively close the eyes leads to corneal exposure and excessive evaporation of the tear film. The main causes of lagophthalmos are facial nerve palsy, trauma, eyelid surgery, senile ectropion, and Graves' ophthalmopathy. An incomplete blink and lagophthalmos frequently occur after upper eyelid ptosis correction, and occur less often following upper and lower blepharoplasty surgery. ${ }^{2}$ One of the goals when treating lagophthalmos is to prevent exposure keratitis. Conventional treatments for mild lagophthalmos are artificial tears or ointment, lubricating prophylactic antibiotics, moist chambers, adhesive tape, and eye patches. Especially for severe lagophthalmos due to complete facial nerve palsy, surgical procedures have been recommended, such as upper eyelid gold-weight implants ${ }^{3,4}$ and tarsorrhaphy. ${ }^{5}$

The tear film is composed of a lipid layer overlying an aqueous layer that is a mixture of lacrimal fluid and mucins. ${ }^{6}$ On the ocular surface, mucins are classified into two types. One is secreted mucin that is supplied from conjunctival goblet cells, and the other is membrane-associated mucin, which appears on the surface of the cornea and conjunctival epithelium. ${ }^{7}$ The therapeutic effects of rebamipide are owing to its ability to increase corneal and conjunctival mucin-like substances and improve corneal and conjunctival injury in vivo., 
It has been shown that rebamipide increases mucin production in cultured conjunctival goblet cells ${ }^{10,11}$ and corneal epithelial cells. ${ }^{12}$ These reports have also indicated that rebamipide increases the secretion of both membraneassociated and secreted-type mucins. Rebamipide is an antiulcer agent that has been used to treat gastric ulcers and gastritis since 1990 in Japan. ${ }^{13}$ Rebamipide has been shown to increase gastric endogenous prostaglandin E2 and I2 to promote gastric epithelial mucin, ${ }^{14,15}$ behaving as an oxygen-free radical scavenger ${ }^{16,17}$ and an anti-inflammatory agent. ${ }^{18,19}$

Recently, the clinical effects of rebamipide eye drops (Mucosta ophthalmic suspension UD2\%; Otsuka Pharmaceutical Co, Tokyo, Japan) for dry eye were reported. ${ }^{20,21}$ Rebamipide eye drops for dry eye are also being developed for approved use in the US. In this study, we investigated the effect of topical rebamipide on corneal disorders subsequent to corneal exposure and excessive evaporation of the tear film in mild lagophthalmos.

\section{Methods}

We consecutively observed seven eyes of seven cases (three males and four females) with mild lagophthalmos during the treatment of corneal disorders with rebamipide from JuneDecember 2012 in Maebashi Red Cross Hospital.

The subjects' ages ranged from 62 years to 85 years (mean 72.4 years). In all seven cases, inferior corneal erosion had occurred from mild lagophthalmos before the administration of rebamipide. Rebamipide eye drops were administered four times daily for 2 weeks; other eye drops used before the administration of rebamipide were stopped.

Causes of lagophthalmos were eyelid surgery in three cases, incomplete facial nerve palsy in two cases, and senile ectropion in two cases. Among the three cases of postoperative lagophthalmos, in Case 1, levator aponeurosis advancement was performed for senile ptosis at another hospital 2 weeks prior to the study. Eye pain from inferior corneal erosion was not improved by sodium hyaluronate ophthalmic solution. Case 2 had levator resection for senile ptosis in our hospital 1 month prior to the study. Although the eyelid was frequently moisturized by antibiotic ointment after surgery, eye pain suddenly occurred from inferior corneal erosion 1 month after surgery. In the remaining case (Case 4), after multiple surgeries for entropion in another hospital many years prior, inferior corneal erosion persistently existed despite treatment with sodium hyaluronate ophthalmic solution, and the patient had a persistent feeling of dryness.

Two cases of incomplete facial nerve palsy, one with idiopathic facial nerve palsy (Case 3 ) and the other with facial nerve palsy as a result of surgery for a brain tumor several years prior (Case 5), were treated with sodium hyaluronate ophthalmic solution by other doctors for several months. Both experienced dryness, and one also had blurred vision because of a cataract.

Two cases with senile ectropion had a feeling of foreign body sensation (Cases 6 and 7). One patient with ectropion had been treated with an antibiotic ointment for 3 months; the other had received no treatment. The detailed profiles of the subjects are summarized in Table 1.

The fluorescein corneal staining (FCS) score, tear film break-up time (TBUT), Schirmer's test, and decimal visual acuity were examined before and 2 weeks after administrations of rebamipide. For FCS and TBUT, corneal staining with fluorescein solution was examined under standard illumination using a slit-lamp microscope with a cobalt blue filter. The cornea was divided into five parts, each of which was given an attaining score from 0 to 3 , and the total score was calculated as described in a previous report. ${ }^{21}$ TBUT was measured three times using a stopwatch as the time from normal blinking to the first appearance of a dry spot in the tear film. Schirmer's test was performed to measure tear volume.

Ocular symptoms were examined by questioning each patient before and 2 weeks after administration of the drug. The symptoms were scored from 0 to 4 , where a score of 0 indicated no symptoms and a score of 4 indicated very severe symptoms, as described in a previous report. ${ }^{21}$

All values are expressed as the mean \pm standard error and the range. The differences between the groups were analyzed with a Wilcoxon signed-rank test. $P$-values less than 0.05 were considered significant.

The study was conducted according to the tenets of the Declaration of Helsinki. The institutional review board ethics

Table I Profiles of each subject

\begin{tabular}{|c|c|c|c|c|}
\hline Case & Age & Sex & $\begin{array}{l}\text { Cause of mild } \\
\text { lagophthalmos }\end{array}$ & $\begin{array}{l}\text { Previous treatment/ } \\
\text { comments }\end{array}$ \\
\hline $\mathrm{I}$ & 83 & Female & $\begin{array}{l}\text { Levator aponeurosis } \\
\text { advancement }\end{array}$ & $\mathrm{SH}$ \\
\hline 2 & 72 & Male & Levator resection & $\mathrm{AO}$ \\
\hline 3 & 69 & Female & $\begin{array}{l}\text { Idiopathic facial } \\
\text { nerve palsy }\end{array}$ & $\mathrm{SH}$ \\
\hline 4 & 62 & Female & Entropion surgery & $\mathrm{SH}$ \\
\hline 5 & 64 & Female & $\begin{array}{l}\text { Postoperative facial } \\
\text { nerve palsy }\end{array}$ & $\mathrm{SH} /$ senile cataract \\
\hline 6 & 85 & Male & Senile ectropion & $\mathrm{AO}$ \\
\hline 7 & 72 & Male & Senile ectropion & Senile cataract \\
\hline
\end{tabular}

Abbreviations: $\mathrm{AO}$, antibiotic ointment; $\mathrm{SH}$, sodium hyaluronate ophthalmic solution. 
committee (Red Cross Hospital) approved the study. All individuals provided informed consent after having received a detailed explanation of the purpose of the study.

\section{Results}

In all seven eyes, inferior corneal erosion decreased or disappeared within 2 weeks after the administration of topical rebamipide eye drops (Figures 1-4). FCS scores, TBUT results, and Schirmer's test results for each patient are shown in Table 2. FCS scores after administration of the drug (range: 0-1 second, mean: $0.7 \pm 0.2$ seconds) were significantly improved compared to FCS scores before administration of the drug (range: $1-5$ seconds, mean: $2.9 \pm 0.6$ seconds; $P<0.05$ ). TBUT results after administration of the drug (range: 3.4-6.5 seconds, mean: $5.2 \pm 0.4$ seconds) were significantly extended compared to TBUT results before administration of the drug (range: 1.5-4.3 seconds, mean: $2.9 \pm 0.5$ seconds; $P<0.05$ ). There were no significant differences in Schirmer's test results before and after the administration of rebamipide.

The ocular symptoms, scores of the symptoms, and decimal visual acuity before and after the administration of rebamipide eye drops are shown in Table 3. The symptom scores were significantly improved after administration of the drug (range: $0-1$ second, mean: $0.7 \pm 0.2$ seconds) compared with those before administration of the drug (range: 2-4 seconds, mean: $2.9 \pm 0.3$ seconds; $P<0.05$ ). In Cases 1 and 2, the complaints of eye pain disappeared within 2 weeks after administration of rebamipide. In Cases 3, 4, and 5 , feelings of dryness were improved within 2 weeks after administration of the drug; Case 5, with a senile cataract,

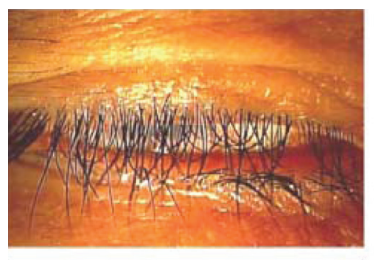

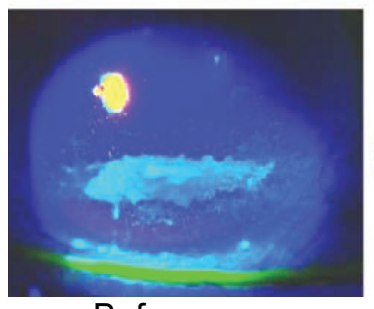

Before

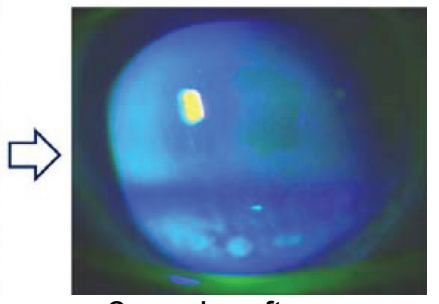

2 weeks after
Figure I 83-year-old female (Case I).

Notes: The inferior cornea was slightly exposed with mild lagophthalmos after levator aponeurosis advancement (upper). Fluorescein corneal staining showed that inferior corneal erosions were remarkably decreased within 2 weeks after the administration of topical rebamipide eye drops (lower).

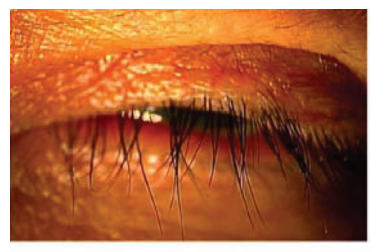

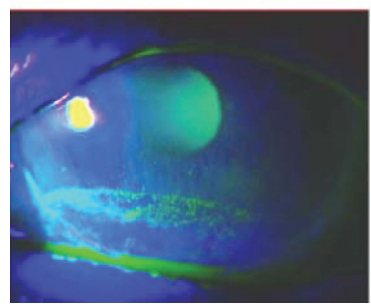

Before

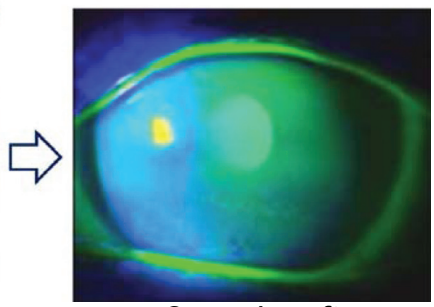

2 weeks after
Figure 2 72-year-old male (Case 2).

Notes: The inferior cornea was slightly exposed with mild lagophthalmos after the advancement of levator resection (upper). Fluorescein corneal staining showed that inferior corneal erosions were decreased and wettability was improved within 2 weeks after the administration of topical rebamipide eye drops (lower).

was aware of an improvement in vision, although the decimal visual acuity was not improved. In Cases 6 and 7, foreign body sensations were improved gradually after administration of rebamipide.

\section{Discussion}

Normal lid anatomy and closure are critical to prevent evaporation of the normal tear film. ${ }^{22}$ Wettability of the corneal epithelial surface and properties of tear fluids have been regarded as principal factors in the determination of precorneal tear film stability. ${ }^{23,24}$ The inability to blink and effectively close the eyes leads to corneal exposure and excessive evaporation of the tear film. ${ }^{1}$ Membrane-associated mucin expressed from the epithelium contributes to wettability of the corneal epithelial surface. ${ }^{25}$ Rebamipide increases mucin production from conjunctival goblet cells ${ }^{10,11}$ and corneal epithelial cells. ${ }^{12}$ Kinoshita et al reported that the administration of rebamipide is an effective treatment for dry eye ${ }^{21}$ Rebamipide may also improve wettability of the corneal surface and tear film stability in mild lagophthalmos.

In our current study, we reported the effect of rebamipide eye drops for corneal disorders in mild lagophthalmos for the first time. After administration of rebamipide eye drops, corneal erosions disappeared or were decreased, TBUT was significantly extended, and symptoms were improved in all seven cases. From these results, we speculate that rebamipide increased tear stability via increased mucin secretion, which contributed to improving corneal erosion due to lagophthalmos.

In four of seven eyes, although treatments with sodium hyaluronate ophthalmic solution were performed before the 


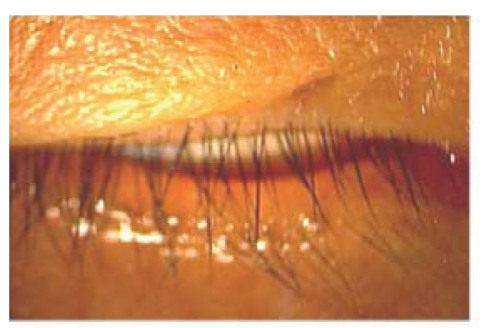

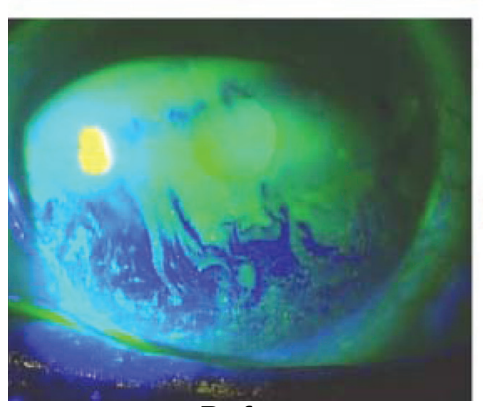

Before

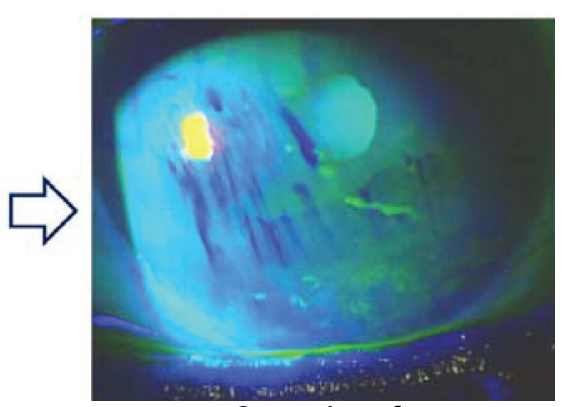

2 weeks after

Figure 3 69-year-old female (Case 3).

Notes: The inferior cornea was slightly exposed with mild lagophthalmos from facial nerve palsy (upper). Fluorescein corneal staining showed that inferior corneal erosions and dry areas were decreased within 2 weeks after the administration of topical rebamipide eye drops (lower).

first visit to our hospital, improvements in corneal disorders and complaints were not improved enough. In two cases, antibiotic ointments were administrated to prevent corneal exposure before rebamipide treatment. Rebamipide eye drops may become a first choice for patients that have

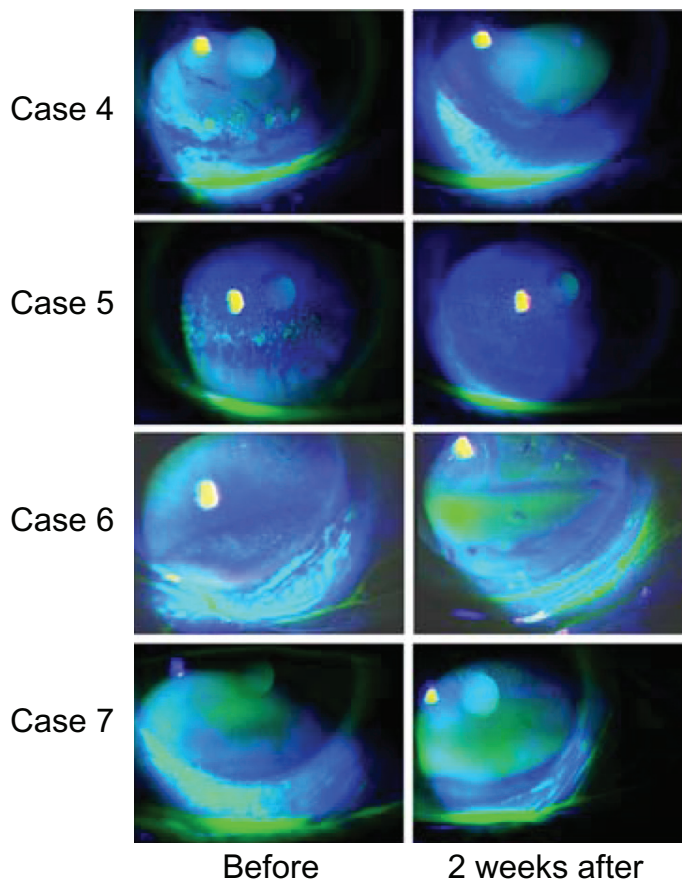

Figure 4 Cases 4, 5, 6, and 7 .

Notes: In all four cases, fluorescein corneal staining showed that inferior corneal erosions were decreased or disappeared within 2 weeks after the administration of topical rebamipide eye drops. lagophthalmos, rather than other eye drops or ointments. In this study, the number of the patients was small, with no control groups, and corneal disorders were limited to only the inferior cornea because of mild lagophthalmos. Further investigations should incorporate a greater number of cases, including severe lagophthalmos with control groups.

Diquafosol sodium eye drops also increase secretion of mucins and improve tear film stability in the short TBUT type of dry eye. ${ }^{26,27}$ Diquafosol sodium eye drops may be useful for mild lagophthalmos.

Previous studies have demonstrated that rebamipide has various anti-inflammatory effects, including the suppression of inflammatory cytokine production by monocytes ${ }^{19}$ and suppression of free-radical scavenging activity. ${ }^{16}$ The exposed ocular surface may induce chronic inflammation.

Table 2 Clinical data before and after rebamipide eye drops

\begin{tabular}{|c|c|c|c|c|c|c|}
\hline \multirow[t]{2}{*}{ Case } & \multicolumn{2}{|l|}{$\begin{array}{l}\text { FCS } \\
\text { score }\end{array}$} & \multicolumn{2}{|l|}{$\begin{array}{l}\text { TBUT } \\
\text { (sec) }\end{array}$} & \multicolumn{2}{|c|}{$\begin{array}{l}\text { Schirmer's } \\
\text { test (mm) }\end{array}$} \\
\hline & Before & After & Before & After & Before & After \\
\hline 1 & 5 & 1 & 1.8 & 5.2 & 12 & 15 \\
\hline 2 & 4 & 1 & 1.6 & 3.9 & 17 & 16 \\
\hline 3 & 3 & I & 4.2 & 6.4 & 20 & 16 \\
\hline 4 & 3 & 1 & 1.5 & 3.4 & 6 & 7 \\
\hline 5 & 3 & I & 4.3 & 6.5 & 17 & 19 \\
\hline 6 & 1 & 0 & 2.6 & 5.2 & 9 & 9 \\
\hline 7 & I & 0 & 4.0 & 5.8 & II & 12 \\
\hline
\end{tabular}

Abbreviations: FCS, fluorescein corneal staining; sec, seconds; TBUT, tear film break-up time. 
Table 3 Ocular symptoms and visual acuities before and after rebamipide eye drops

\begin{tabular}{lllllll}
\hline Case & Ocular symptom & \multicolumn{2}{l}{$\begin{array}{l}\text { Symptom } \\
\text { score }\end{array}$} & & \multicolumn{2}{l}{$\begin{array}{l}\text { Visual } \\
\text { acuity }\end{array}$} \\
\cline { 3 - 4 } \cline { 6 - 7 } \cline { 6 - 7 } & & Before & After & Before & After \\
\hline I & Eye pain & 4 & 0 & 0.7 & 0.9 \\
2 & Eye pain & 3 & 0 & & 1.0 & 1.2 \\
3 & Dryness & 3 & $\mathrm{I}$ & 0.8 & 0.8 \\
4 & Dryness & 2 & $\mathrm{I}$ & & 1.0 & 1.2 \\
5 & Dryness, blurred vision & 3 & $\mathrm{I}$ & 0.2 & 0.2 \\
6 & Foreign body sensation & 2 & $\mathrm{I}$ & 0.7 & 1.0 \\
7 & Foreign body sensation & 2 & $\mathrm{I}$ & 0.3 & 0.3 \\
\hline
\end{tabular}

After eyelid surgery, inflammation of the eyelid may be entangled with disorders of the cornea and the conjunctiva. Rebamipide may reduce inflammation of the eyelid and improve the ocular surface.

Transient impairment of Bell's phenomenon has been reported in cases after levator resection for blepharoptosis. ${ }^{28}$ In Cases 1 and 2 of our study, postoperative wound contraction and insufficient Bell's phenomenon may transiently influence the pathogenesis of inferior corneal erosion. In these cases, restoration of Bell's phenomenon may encourage the therapeutic effect of rebamipide.

Visual acuities were evaluated using decimal visual acuity measurements. There was no significant improvement in the visual acuities of the seven eyes. In Case 5, the patient was aware of improvement in vision despite no change in decimal visual acuity. Kaido et al reported that functional visual acuity measurements are useful for patients with dry eye. ${ }^{29}$ Functional visual acuity might have demonstrated improvement of visual acuity in this study.

The tear film is composed of a lipid layer overlying an aqueous layer that is a mixture of lacrimal fluid and mucins. ${ }^{6}$ The secretion of lipids from the meibomian gland serves the lipid layer. Blinking is related to meibomian gland function. ${ }^{30}$ Meibography can assess the relation between morphological changes and the eyelid and tear film parameters. ${ }^{31,32}$ Meibography may also be useful in examining meibomian gland function with lagophthalmos. Low-dose lipid ointment application may improve dry eye. ${ }^{33}$ Although sufficient effects were not obtained with ointments or sodium hyaluronate ophthalmic solution alone before administration of rebamipide in our study, ointment and artificial tears may be effective after stabilization of corneal wettability. The combination of ointments, artificial tears, and rebamipide eye drops may be a more appropriate method in the treatment of lagophthalmos.

\section{Disclosure}

The authors did not receive any grants or funds to undertake this study. They report no proprietary interest in this report, and no other conflicts of interest.

\section{References}

1. Pereira MV, Glória AL. Lagophthalmos. Semin Ophthalmol. 2010;25(3): $72-78$.

2. Klapper SR, Patrinely JR. Management of cosmetic eyelid surgery complications. Semin Plast Surg. 2007;21(1):80-93.

3. Sansone V, Boynton J, Palenski C. Use of gold weights to correct lagophthalmos in neuromuscular disease. Neurology. 1997;48(6):1500-1503.

4. Patel V, Daya SM, Lake D, Malhotra R. Blink lagophthalmos and dry eye keratopathy in patients with non-facial palsy: clinical features and management with upper eyelid loading. Ophthalmology. 2011;118(1): 197-202.

5. Putterman AM. Suture tarsorrhaphy system to control keratopathy after ptosis surgery. Ophthalmic Surg. 1980;11(9):577-580.

6. Gipson IK. The ocular surface: the challenge to enable and protect vision. The Friedenwald lecture. Invest Ophthalmol Vis Sci. 2007; 48(10):4390-4398.

7. Gipson IK. Distribution of mucins at the ocular surface. Exp Eye Res. 2004;78(3):379-388.

8. Urashima H, Okamoto T, Takeji Y, Shinohara H, Fujisawa S Rebamipide increases the amount of mucin-like substances on the conjunctiva and cornea in the $\mathrm{N}$-acetylcysteine-treated in vivo model. Cornea. 2004;23(6):613-619.

9. Tanito M, Takanashi T, Kaidzu S, Yoshida Y, Ohira A. Cytoprotective effects of rebamipide and carteolol hydrochloride against ultraviolet B-induced corneal damage in mice. Invest Ophthalmol Vis Sci. 2003;44(7):2980-2985.

10. Rios JD, Shatos M, Urashima H, Tran H, Dartt DA. OPC-12759 increases proliferation of cultured rat conjunctival goblet cells. Cornea. 2006; 25(5):573-581.

11. Rios JD, Shatos MA, Urashima H, Dartt DA. Effect of OPC-12759 on EGF receptor activation, p44/p42 MAPK activity, and secretion in conjunctival goblet cells. Exp Eye Res. 2008;86(4):629-636.

12. Takeji Y, Urashima H, Aoki A, Shinohara H. Rebamipide increases the mucin-like glycoprotein production in corneal epithelial cells. J Ocul Pharmacol Ther. 2012;28(3):259-263.

13. Uchida M, Tabusa F, Komatsu M, Morita S, Kanbe T, Nakagawa K. Studies on $2(1 \mathrm{H})$-quinolinone derivatives as gastric antiulcer active agents. 2-(4-Chlorobenzoylamino)-3-[2(1H)-quinolinon-4-yl]propionic acid and related compounds. Chem Pharm Bull (Tokyo). 1985;33(9): 3775-3786.

14. Yamasaki K, Kanbe T, Chijiwa T, Ishiyama H, Morita S. Gastric mucosal protection by OPC-12759, a novel antiulcer compound, in the rat. Eur J Pharmacol. 1987;142(1):23-29.

15. Kleine A, Kluge S, Peskar BM. Stimulation of prostaglandin biosynthesis mediates gastroprotective effect of rebamipide in rats. Dig Dis Sci. 1993;38(8):1441-1449.

16. Yoshikawa T, Naito Y, Tanigawa T, Kondo M. Free radical scavenging activity of the novel anti-ulcer agent rebamipide studied by electron spin resonance. Arzneimittelforschung. 1993;43(3):363-366.

17. Naito Y, Yoshikawa T, Tanigawa T, et al. Hydroxyl radical scavenging by rebamipide and related compounds: electron paramagnetic resonance study. Free Radic Biol Med. 1995;18(1):117-123.

18. Arakawa T, Kobayashi K. Quality of ulcer healing - a new concept to rank healed peptic ulcers. Gastroenterol Jpn. 1993;28 Suppl 5: 158-162.

19. Aihara M, Imagawa K, Funakoshi Y, Ohmoto Y, Kikuchi M. Effects of rebamipide on production of several cytokines by human peripheral blood mononuclear cells. Dig Dis Sci. 1998;43(Suppl 9):160S-166S. 
20. Kashima T, Akiyama H, Miura F, Kishi S. Resolution of persistent corneal erosion after administration of topical rebamipide. Clin Ophthalmol. 2012;6:1403-1406.

21. Kinoshita S, Awamura S, Oshiden K, et al. Rebamipide (OPC-12759) in the treatment of dry eye: a randomized, double-masked, multicenter, placebo-controlled Phase II study. Ophthalmology. 2012;119(12): 2471-2478.

22. Terry MA. Dry eye in the elderly. Drugs Aging. 2001;18(1):101-107.

23. Holly FJ, Lemp MA. Wettability and wetting of corneal epithelium. Exp Eye Res. 1971;11(2):239-250.

24. Tiffany JM, Winter N, Bliss G. Tear film stability and tear surface tension. Curr Eye Res. 1989;8(5):507-515.

25. Gipson IK, Hori Y, Argüeso P. Character of ocular surface mucins and their alteration in dry eye disease. Ocul Surf. 2004;2(2):131-148.

26. Shimazaki-Den S, Iseda H, Dogru M, Shimazaki J. Effects of diquafosol sodium eye drops on tear film stability in short BUT type of dry eye. Cornea. Epub May 31, 2013.

27. Takamura E, Tsubota K, Watanabe H, Ohashi Y; Diquafosol Ophthalmic Solution Phase 3 Study Group. A randomised, double-masked comparison study of diquafosol versus sodium hyaluronate ophthalmic solutions in dry eye patients. Br J Ophthalmol. 2012;96(10):1310-1315.
28. Betharia SM, Sharma V. Inverse Bell's phenomenon observed following levator resection for blepharoptosis. Graefes Arch Clin Exp Ophthalmol. 2006;244(7):868-870.

29. Kaido M, Ishida R, Dogru M, Tsubota K. The relation of functional visual acuity measurement methodology to tear functions and ocular surface status. Jpn J Ophthalmol. 2011;55(5):451-459.

30. Korb DR, Baron DF, Herman JP, et al. Tear film lipid layer thickness as a function of blinking. Cornea. 1994;13(4):354-359.

31. Arita R, Itoh K, Maeda S, Maeda K, Tomidokoro A, Amano S. Efficacy of diagnostic criteria for the differential diagnosis between obstructive meibomian gland dysfunction and aqueous deficiency dry eye. Jpn J Ophthalmol. 2010;54(5):387-391.

32. Arita R, Itoh $\mathrm{K}$, Maeda S, Maeda K, Tomidokoro A, Amano S. Association of contact lens-related allergic conjunctivitis with changes in the morphology of meibomian glands. Jpn JOphthalmol. 2012;56(1): 14-19.

33. Goto E, Dogru M, Fukagawa K, et al. Successful tear lipid layer treatment for refractory dry eye in office workers by low-dose lipid application on the full-length eyelid margin. Am J Ophthalmol. 2006;142(2):264-270.
Clinical Ophthalmology

\section{Publish your work in this journal}

Clinical Ophthalmology is an international, peer-reviewed journal covering all subspecialties within ophthalmology. Key topics include: Optometry; Visual science; Pharmacology and drug therapy in eye diseases; Basic Sciences; Primary and Secondary eye care; Patient Safety and Quality of Care Improvements. This journal is indexed on Submit your manuscript here: http://www.dovepress.com/clinical-ophthalmology-journal

\section{Dovepress}

PubMed Central and CAS, and is the official journal of The Society of Clinical Ophthalmology (SCO). The manuscript management system is completely online and includes a very quick and fair peer-review system, which is all easy to use. Visit http://www.dovepress.com/ testimonials.php to read real quotes from published authors. 